\title{
A VOZ DE UMA LIDERANÇA INDÍGENA FEMININA SOBRE A QUESTÃO DE GÊNERO - UMA OPORTUNIDADE DE ESCUTA E REFLEXÃO PARA A PESQUISA ETNOBIOLÓGICA
}

\section{THE VOICE OF A FEMALE INDIGENOUS LEADER ON GENDER ISSUES - AN OPPORTUNITY FOR LISTENING AND REFLECTION FOR ETHNOBIOLOGICAL RESEARCH}

\author{
Sofia ZANK $^{1 *}$; Kerexu YXAPYRY ${ }^{2}$
}

${ }^{1}$ Universidade Federal de Santa Catarina, Departamento de Ecologia e Zoologia, Laboratório de Ecologia Humana e Etnobotânica, Florianópolis, Santa Catarina, Brasil. ${ }^{2}$ Liderança Indígena Mbyá Guarani, Terra Indígena Morro dos Cavalos.*sofiazank@gmail.com

Submitted: 09/10/2020; Accepted: 18/11/2020; Published: 09/04/2021

\section{INTRODUÇÃO}

Os estudos feministas destacam, há algumas décadas, as assimetrias estabelecidas entre as relações de gênero, em um processo associado à privatização da terra, colonização, capitalismo e dominação do corpo feminino (FEDERICI, 2017). O reconhecimento da interconexão entre diferentes sistemas de opressão, através do conceito de interseccionalidade, evidencia a importância de tratar as assimetrias de gênero associadas a outros sistemas de opressão, como raça, etnia e classe (GAARD, 2011). O ecofeminismo, em uma de suas vertentes, amplia ainda mais esta perspectiva de interconexão dos sistemas de opressão, ao vincular a exploração da natureza à dominação do feminino e da mulher (GAARD, 2011).

Neste contexto, considero ${ }^{1}$ que as discussões de gênero, quando realizadas de forma integrada e interconectada, podem nos levar ao estabelecimento de sociedades com maior equidade e respeito à diversidade biocultural. A etnobiologia - pode trazer contribuições importantes para diminuir as relações de opressão nas suas diversas esferas, ao reverberar as vozes que por muito tempo foram caladas ou ignoradas, entre estas, as dos povos indígenas e tradicionais e de suas representantes mulheres. Conforme abordado por Ribeiro (1999, p.42), a história tem mostrado que a invisibilidade mata, e que quando as mulheres negras e indígenas estão "reivindicando o direito a ter voz, elas estão reivindicando o direito à própria vida".

\footnotetext{
${ }^{1}$ As partes iniciais do artigo foram escritas na $1^{\text {a }}$ pessoa do singular, pois dizem respeito a trajetória e opinião da primeira autora.
} 
É neste contexto que busco, através deste texto, oportunizar um lugar de fala para o povo Guarani em relação ao gênero, através da liderança indígena Kerexu Yxapyry. Kerexu é uma mulher encantadora, de muita força e amorosidade. Ela foi a primeira Cacica Guarani reconhecida no Brasil, é mãe, professora, gestora ambiental pela Universidade Federal de Santa Catarina, liderança da Terra Indígena Morro dos Cavalos (Palhoça, SC), no ano de 2018 concorreu a deputada federal e atualmente faz parte da coordenação da Comissão Guarani Yvyrupa e da coordenação executiva da Articulação dos Povos Indígenas do Brasil (APIB).

\section{INTRODUCTION}

Feminist studies have highlighted, for some decades, the asymmetries established in gender relations, in a process associated with land privatization, colonization, capitalism and domination of the female body (FEDERICI, 2017). Recognition of the interconnection between different systems of oppression, through the concept of intersectionality, highlights the importance of addressing gender asymmetries associated with other systems of oppression, such as race, ethnicity and class (GAARD, 2011). Ecofeminism, in one of its aspects, further expands this perspective of interconnection of systems of oppression, by linking the exploration of nature to the domination of the feminine and of women (GAARD, 2011).

In this context, I consider that gender discussions, when carried out in an integrated and interconnected way, can lead to the establishment of societies with greater equity and respect for biocultural diversity. Ethnobiologycan bring important contributions to reduce oppression in its various spheres, by reverberating the voices that have long been silent or ignored, amongst these are the voices of indigenous and traditional peoples, and their female representatives. As addressed by Ribeiro (1999, p.42), history has shown that invisibility kills, and that when black and indigenous women are "claiming the right to have a voice, they are claiming the right to their own life."

It is in this context, through this text, that I seek to provide a place to be heard, for the Guarani people in relation to gender, through the indigenous leader Kerexu Yxapyry. Kerexu is a charming and lovely woman of great strength. She was the first Cacica Guarani recognized in Brazil, is a mother, a teacher, an environmental manager with the Federal University of Santa Catarina, and the leader of the Indigenous Lands of Morro dos Cavalos (Palhoça, SC). In 2018 she ran for federal deputy (congress) and is currently part of the 
coordination of both the Guarani Yvyrupa Commission and of the Articulation of Indigenous Peoples of Brazil (APIB).

\section{OS CAMINHOS QUE NOS LEVARAM A ESTE ESPAÇO DE ESCUTA}

Conheci Kerexu no ano de 2012, durante uma experiência no curso de graduação em Licenciatura Intercultural Indígena do Sul da Mata Atlântica. Na época, eu era doutoranda do Laboratório de Ecologia Humana e Etnobotânica e fui convidada a participar da disciplina de Biodiversidade e Sociodiversidade, coordenada pelas professoras Natalia Hanazaki e Bárbara Segal e pelo professor Nivaldo Peroni. A disciplina foi ministrada para três turmas: Guarani, Kaingang e Xokleng/Laklãnõ. Foi uma experiência de grande aprendizado, pois me possibilitou refletir e repensar o processo de ensino aprendizagem nos espaços acadêmicos e de como possibilitar a inclusão efetiva dos povos indígenas e tradicionais. Como exemplos de aprendizados dessa experiência poderia citar a importância de valorizarmos a comunicação oral, através das línguas indígenas nos espaços acadêmicos, e de possibilitar a presença das crianças na sala de aula, acompanhando as mães e pais. Kerexu, que já era Cacica da Terra Indígena (TI) Morro dos Cavalos, participou da turma Guarani e trazia muitas colocações e questionamentos nas aulas, de uma forma amável e ao mesmo tempo certeira.

Depois desta experiência com a licenciatura indígena, fiquei algum tempo sem ver e falar com Kerexu. Acompanhava, através de notícias e das redes sociais, a luta pela demarcação do território na TI Morro dos Cavalos e a violência e as ameaças que Kerexu precisou enfrentar para defender a sua comunidade e o direito de existir. No âmbito do laboratório de Ecologia Humana e Etnobotânica, aconteceram algumas outras parcerias com a Kerexu e a TI, como as pesquisas de mestrado sobre orquídeas de Blanco (2017) e sobre o intercâmbio de plantas medicinais pelos indígenas Mbyá Guarani no sul do Brasil de Andrade (2019), sendo que na última, Kerexu participou da banca examinadora (Figura $1 \mathrm{~A})$.

Voltei a me aproximar da Kerexu no ano de 2018, em um contexto não acadêmico. Nesta época, Kerexu era candidata a deputada federal, e a convidamos para participar do programa Vozes da Lua na rádio comunitária do Campeche (Florianópolis/SC) para discutir sobre a situação política, pois estávamos receosas com as eleições presidenciais. O "Vozes da Lua" é um programa que conduzo com duas amigas, que busca oportunizar espaços de fala e escuta sobre o feminino contemporâneo. 
Naquele programa, ao escutar a voz e os saberes de Kerexu e de seu povo sobre diversos aspectos da vida e da política, fiquei simplesmente encantada. Uma sabedoria e entendimento holístico e integral do mundo que transcendia muitos livros, cientistas e pensadores ocidentais. A partir deste momento, convidamos Kerexu para mais alguns programas de rádio (Figura 1B) e fomos acompanhando mais de perto a expansão política de suas ações na defesa dos direitos dos povos indígenas em eventos nacionais e internacionais.

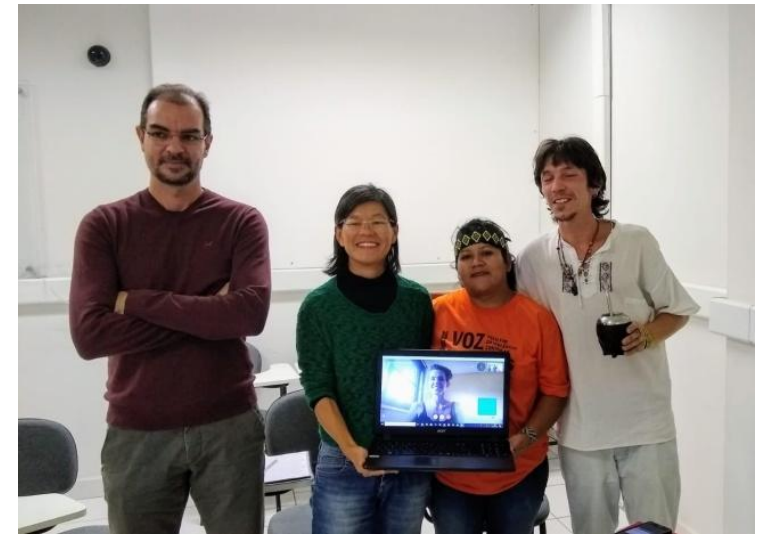

(A)

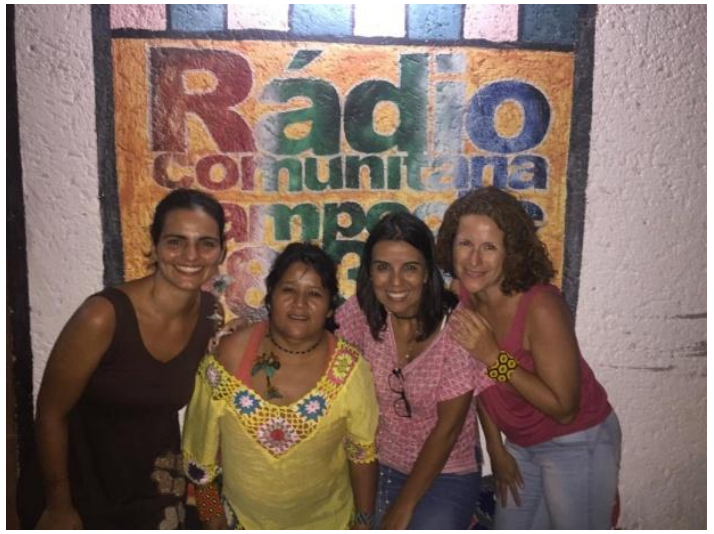

(B)

Figura 1: Registro de parcerias com a Kerexu Yxapary: (A) banca de mestrado do Julian Henrique Carlotto de Andrade, na Universidade Federal de Santa Catarina, em junho de 2019; e (B) em uma das entrevistas na Rádio Comunitária do Campeche, Florianópolis/SC, em março de 2019.

Quando surgiu a chamada para a edição especial da Ethnoscientia "Olhares femininos na Etnobiologia" percebi que a minha maior contribuição poderia ser oportunizar um lugar de fala e de visibilidade para os conhecimentos e vivências da Kerexu relacionados ao gênero. No planejamento desta proposta, minha ideia era realizar a entrevista com a Kerexu de forma presencial. Porém, com a situação de isolamento necessário para o enfrentamento da pandemia do COVID-19, precisamos modificar os planos. A entrevista foi realizada através de uma live em rede social, o que permitiu que a coleta de dados ocorresse junto com a divulgação científica, tudo em um único momento. Foi realizada a transcrição da entrevista e a partir dela foram feitos pequenos ajustes, apenas para adequar as falas ao formato escrito. Espero que com esta entrevista, a voz de Kerexu possa ser como um sopro de esperança nestes tempos difíceis e que nos aproximem de uma ciência e de uma sociedade com maior equidade. 


\section{A ENTREVISTA}

Sofia: - Oi, Kerexu! Seja bem-vinda!

Kerexu: - Oi! Obrigada.

Sofia: - Estou muito feliz com a oportunidade da nossa conversa. Chegou o grande dia, como estávamos comentando hoje cedo. E que bom que existem as tecnologias que permitem nos aproximar nestes tempos difíceis. Vamos iniciar a nossa conversa?

Kerexu: - Vamos!

Sofia: - Neste primeiro momento, gostaríamos que você se apresentasse. Quem é Kerexu Yxapyry? O que você gostaria de compartilhar?

Kerexu: Tá bom! Primeiro eu quero agradecer o convite, pois desde o início, a gente vem criando para realizar esta conversa e na correria do dia a dia acabamos atrasando. Depois veio a pandemia, o que acabou dificultando ainda mais. Bom, mas eu sou Kerexu, liderança aqui na Terra Indígena Morro dos Cavalos. Também estou hoje na Coordenação da Comissão Guarani Yvyrupa (CGY), uma comissão que trabalha com território Guarani de forma conectada no Brasil. Eu gosto de falar sobre território, porque o nosso território Guarani abrange cinco países: Paraguai, Uruguai, Argentina, Bolívia e Brasil. Aqui no Brasil, estamos em oito Estados: Rio Grande do Sul, Santa Catarina, Paraná, São Paulo, Rio de Janeiro, Espírito Santo, Mato Grosso do Sul e Pará. Há cerca de um ano que comecei a trabalhar como coordenadora desta comissão. Hoje também faço parte da coordenação executiva da Articulação dos Povos Indígenas do Brasil(APIB). Em casa, eu sou agricultora, trabalho com a terra e sou apaixonada pelas plantas.

(Resolvendo problemas técnicos)

Sofia: - Bom, vamos seguindo em nossa conversa com a temática de gênero e etnobiologia. Nós (pesquisadoras e pesquisadores) vivenciamos e conhecemos as relações de gênero que ocorrem em nossa cultura ocidental. Mas é importante que a gente conheça e aprenda sobre a visão que outros povos possuem em relação ao gênero. Então, eu gostaria que você nos falasse sobre a visão que o povo Guarani possui sobre gênero, em relação à percepção, aos papéis, entre outras coisas.

Kerexu:- Então, eu acho que quando se trata da questão de gênero é tudo igual. Pelo menos é o que eu percebo no dia a dia, pois eu convivo nestes dois mundos, tanto nessa luta e resistência enquanto mulher indígena e também como liderança que me obriga a entender este outro lado, desse outro mundo não indígena. A dificuldade maior que eu sinto, todo o tempo, é a questão de gênero. Eu entrei como liderança no Morro dos Cavalos foi nesse período da licenciatura mesmo, em 2011, que fui escolhida pra ser Cacica no Morro dos 
Cavalos. Eu já tinha ouvido falar e conhecia algumas Cacicas, mas eu nunca tinha visto como que se fazia esta escolha, como que surgiam essas histórias das mulheres Cacicas. Até que a comunidade me convidou e me escolheu para ser Cacica no Morro dos Cavalos. Até aquele momento, eu atuava como professora na escola, tinha feito curso de magistério, indo e vindo, e aquela função de estar lutando pela questão do direito à educação. Quando eu entrei de Cacica, mudou totalmente a realidade, a minha realidade, porque era uma luta muito maior para defender um território, uma terra com várias famílias e eu era a pessoa responsável por essas famílias. Pra mim, foi muito estranho no início. Aqui em Santa Catarina tem uma comissão de lideranças chamada Nhemonguetá, que é a comissão estadual dos caciques de Santa Catarina. Era muito estranho, porque no estado são 22 aldeias do litoral norte e litoral sul, e eu ia na reunião e era a única mulher, não tinha nenhuma outra mulher. Então, eu chegava nessa reunião e era muito estranho. Até os caciques se sentiam assim, um pouco estranhos, com minha presença ali e eu muito mais. Aí eu comecei a perceber que eles não falavam, não tomavam nenhuma decisão na minha frente. Não sei o porquê! Talvez um dia eu consiga descobrir por qual motivo eles não tomavam decisão na hora da reunião, ficava sempre uma coisa pendente e eu também não falava porque não tinha experiência, ficava acompanhando. Mas eu percebia que quando dava o intervalo, na hora do almoço, as pessoas saíam e eles acabavam fazendo aqueles grupinhos e conversando. Quando voltavam pra reunião, eles já vinham com a decisão formada, pois todo mundo tinha conversado. Então eu era a pessoa que ficava de fora desses assuntos, e eu comecei a achar estranho aquilo. Por que se fazia reunião? E comecei a questionar e tinha uma liderança que vocês devem lembrar, que é o Wera Tupã, o Leonardo, ele falava assim pra mim "Você tem que se impor, você é Cacica! Você tem que falar, você não pode aceitar que as pessoas saiam pra fora pra tomar a decisão e voltem, porque você tem que participar e decidir também. Você é Cacica!’. Aí, então, eu comecei a me impor também. Mas dentro das regras que eu fui educada, dentro da tradição, sempre a mulher tinha que esperar pelo homem, sempre a mulher se submetia ao homem. A mulher não podia tomar decisão sem o homem dar o consentimento, a mulher não poderia levantar e falar na frente dos homens. Toda essa educação que me foi passada era totalmente contra a função que eu estava exercendo naquele momento. Pra mim era muito estranho. Eu ficava imaginando que talvez por isso que não existia cacica. Eu ficava pensando que estava quebrando alguma regra, ferindo alguma norma da tradição Guarani. Então, eu fui conversar com os mais velhos, com os líderes espirituais, pra saber a função da mulher. Por que a mulher foi criada, né? A origem da mulher. Quem criou a mulher e por que ela foi 
criada? E aí foi onde o nosso líder espiritual, o seu Wherá Tupã, também conhecido como Seu Alcindo, falou que a mulher veio para ajudar Nhanderu. A mulher então, ela é uma criadora. Foi muito bonito! Naquele momento, eu entendi o papel da mulher, porque ela é a companheira de Deus. Então imagine, dentro da hierarquia das divindades, existem as divindades, existem os guardiões, existem várias coisas, mas a mulher foi escolhida para ser a companheira de Deus. Então, pense nesse privilégio que a gente tem de ser mulher. No meu entendimento da tradição, ficou pra mulher fazer todo o planejamento e coordenar, porque os homens, na nossa tradição e na nossa cultura, eles são a força que vão parar, que vão fazer, que vão transformar. Os homens são as ações, mas os projetos e planejamentos partem da mulher, porque a mulher tem esse olhar mais amplo. Esse olhar que eu sempre falo que é um olhar de amor. É o olhar de amor que, por exemplo, se alguém atacar seu filho e querer maltratar ele, você vai ter tua defesa, né. Você vai atacar também, você vai proteger. Esse tipo de olhar, que as pessoas, às vezes, falam assim: “Ah, porque a pessoa não pode fazer isso? Porque amor é aquele amor romântico". Não! Amor é isso! É um amor que protege, um amor que está ali na frente, um amor que ajuda. Então esse que é o nosso papel de mulher. Quando eu descobri isso, aí eu falei que agora ninguém mais me segura, porque eu sou a companheira de Deus, e eu vou começar a fazer o meu papel. Foi nesse momento que eu também comecei a quebrar alguns paradoxos que são criados dentro da cultura, porque eu comecei a entender que dentro da mitologia indígena foi criado um outro mito, para colocar a mulher sempre como inferior. A partir daí eu me empoderei como mulher mesmo, como mulher indígena, com a minha função, a minha origem e isso trouxe muita força pra mim na minha luta. Então, pra começar um pouco, essa é a história de como eu, hoje, como mulher indígena, entendo essa questão de gênero. Essa é a história.

Sofia: - Que lindo, Kerexu. Eu já escutei algumas vezes você contar esta história, mas eu sempre me arrepio e me emociono. Eu vi várias pessoas aqui também (nos comentários da live) colocando que é muito lindo, que gostaram muito da tua fala. Outra questão para estarmos refletindo é que hoje se comemora o dia da biodiversidade ( 22 de maio). Não foi por isso que marcamos a conversa no dia de hoje, mas acho oportuno aproveitarmos para falar sobre o papel que as mulheres indígenas possuem na conservação da biodiversidade. Se puder, então, compartilhar com a gente, é importante valorizarmos também este aspecto. Kerexu: - Eu vejo a importância do feminino em toda a natureza. Quando a gente vai falar da biodiversidade, a gente lembra que este sagrado feminino existe em todos os seres vivos, que tem a parte masculina e a parte feminina. A gente depende sempre um do outro, tanto na questão do masculino quanto do feminino, ou do homem e da mulher, falando da questão 
dos humanos. Como eu falei, a mulher tem esse papel de fazer esse planejamento e de criar todo um universo, e nesse universo ela tem que desenhar, traçar caminhos, tramar. Para que as pessoas entendam a nossa função da mulher, nós consideramos que só vai existir um universo se existir esse feminino no meio. Porque os homens, para nós, eles são as estruturas, eles são as bases que vão estruturar todo o universo. Então o nosso papel enquanto mulher é fazer toda essa casa, todo esse sistema funcionar, é o nosso papel enquanto mulher. Dona Rosa, que já não está mais entre nós, nos falava que o universo é como um Ajaka. Para quem não conhece, o Ajaka é uma cesta. Vou até pegar uma aqui para mostrar para vocês. Este é o Ajaka, a cesta (Figura 2).

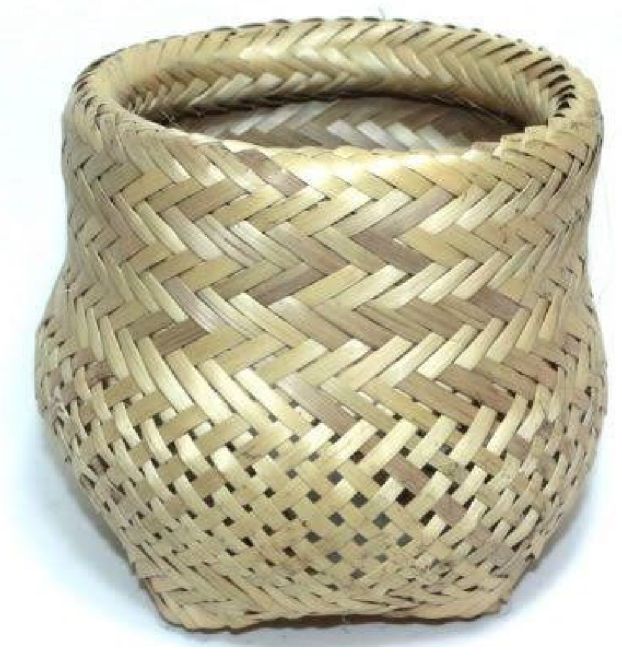

(A)

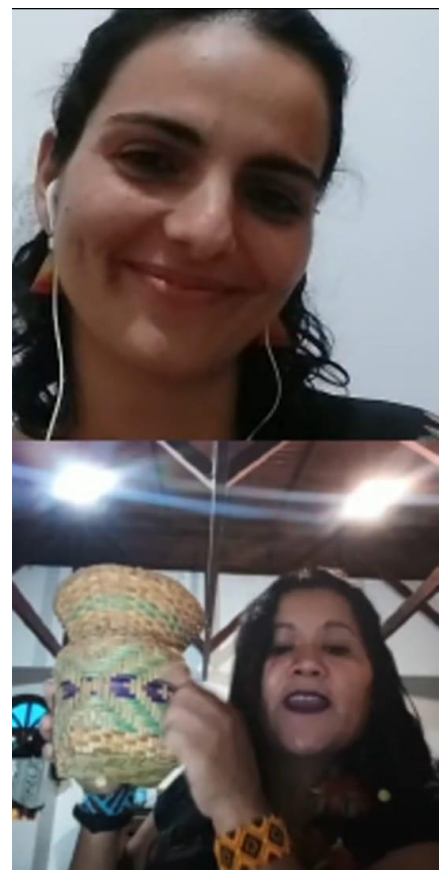

(B)

Figura 2: Ajakaipy'ava'e'y. (A) Balaio tupixi. Fotografia de Juçara de Souza, Morro dos Cavalos, Palhoça/SC, 2020. (B) Kerexu mostrando o Ajaka durante a entrevista (live) em 22 de maio de 2020.

A parte masculina, para nós, vai representar esta parte quadrada aqui em baixo, que é o que vai sustentar o Ajaka. Para eu colocar ela em algum lugar, é o que vai sustentar ela. Daqui (parte inferior e subindo), sai mais uma base que vai segurar e estruturar todo esse Ajaka. Só que não adianta a gente ter essa base e essas estruturas aqui, se a gente não pegar e não fazer a trama, que é o que vai nesse entorno aqui. Aí vocês podem ver que aqui (uma ponta do quadrado inferior) é quadrado, e daqui para cima ele começa a ser circular. Essas somos nós, mulheres. Quando nós, mulheres, vamos tramar, a gente pode desenhar o que a gente quiser, com as cores que a gente quiser. Então esse aqui é um universo. Agora dentro do 
universo eu vou colocar o que eu quiser, também. Então eu preciso da base para sustentar, de toda trama e de todo o desenho e também ter uma utilidade. A gente usa muito para guardar as sementes aqui dentro. As cestas maiores a gente usa para guardar os alimentos. Então assim, veja que universo maravilhoso que nós somos! Esse é o nosso papel, o papel da mulher indígena dentro dessa grande biodiversidade. Porque eu guardando as sementes e colhendo os alimentos, eu consigo sustentar todo este universo. E aí, como que eu vou fazer? Eu só vou usar o necessário, que é pra sobreviver. Nas cestas menores, guardamos e protegemos as sementes pra podermos plantar o alimento. No caso das cestas maiores, é para este universo maior que é a alimentação. Nós mulheres, também somos as guardiãs, porque nós trabalhamos muito com a semente. Na nossa cultura, o espírito da planta vem a partir do nome de uma mulher. No mês de agosto ou setembro, a gente faz o Nhemongarai das sementes, que é a consagração das sementes. Pois o mês de setembro, pra nós, é o ano novo Guarani. No ano novo Guarani, toda a natureza se renova. Vocês vão começar a observar a natureza, vocês vão ver que tudo se renova. Aquelas folhas velhas que agora (maio) estão caindo, vão adubar a terra, vão ser levadas pelo vento, e a partir do final de agosto e início de setembro, começam a brotar as folhas novas, as flores que estão vindo e nós também com a questão da alimentação. A gente consagra as sementes para plantar na terra e poder depois colher os frutos e o alimento. Então, nós, mulheres, quando vamos levar as sementes no altar pra serem consagradas, nós falamos o nosso nome. Se eu vou levar as minhas sementes, da minha família, eu chego e apresento a semente com o nome de Kerexu, que é o meu espírito. Lá, ela vai ser consagrada, e a partir do momento que for consagrada, ela vai ser curada, ela vai ser benzida, tirado todo o mal da semente e aí é devolvida pra mim depois. No dia seguinte, eu enterro, como se estivesse sacrificando aquela semente, que morreu a parte velha e que está vindo a parte nova. A semente mestra pra nós é o milho, o Avaxi. O milho, então, é a semente mestra e não pode faltar Avaxi numa cerimônia de Nhemongaraí. Todas as outras sementes vão estar sendo consagradas nesse período. Depois disso, no período da colheita, é o momento que a gente faz a consagração do alimento, daquela semente que a gente consagrou, a gente vai fazer o alimento. Vamos levar, de novo, na casa de reza pra fazer a consagração do alimento. Nesse momento da consagração do alimento, nós, mulheres, vamos levar o alimento que a gente vai produzir a partir daquelas sementes. Se for o milho é o bolo de milho; a pamonha, a bebida do milho, tudo de milho a gente leva. Então nós, mulheres, vamos fazer esse processo da alimentação, da semente se transformar em alimento. Nesse momento de colheita, os homens vão levar as sementes do milho, que vão ser guardadas para que, no 
outro ano novo, as mulheres consagrarem de novo. Nessa consagração do alimento, nós também nos tornamos sagrados, pois aquele mal que foi tirado lá no início, na semente, tornou o alimento sagrado. Quando nos alimentarmos daquilo, ele vai servir para consagrar o nosso corpo. Neste momento, os espíritos do povo Guarani descem de novo, e as crianças são batizadas e recebem estes espíritos. Gente, eu adoro essa questão da minha cultura! Pensar na função que nós mulheres temos, mas também fazer com que as pessoas, que os homens e que outras pessoas, valorizem esse papel da mulher. Porque se existe ainda a cultura, se existe a língua, se existe o espírito Guarani, eles só estão vindo porque existem mulheres. Então esse é o nosso papel enquanto mulher indígena e a nossa função dentro da nossa comunidade e é muito seguida, todo ano a gente faz isso. A gente também tem a parte de proteção das sementes, de fazer a troca das sementes, de fazer a semente se movimentar. Por exemplo, se a gente fez uma colheita agora, a gente tem que fazer essa semente chegar em todas as outras aldeias. Então tem esta parte da mobilidade, de fazer com que as nossas sementes cheguem em outros lugares e que as sementes de outros lugares cheguem até nós. A gente sempre faz a mobilidade, e nós estamos em um período de mobilidade agora. $\mathrm{O}$ tempo da mobilidade é o tempo da troca das sementes. Nós fizemos essa mobilidade porque nós acreditamos que quando algo fica intacto num lugar só, ou ele está com uma deficiência, ou está doente ou está morto. Assim como nosso corpo, nosso físico, tudo tem que estar em movimento. Se parar de funcionar algum órgão do nosso corpo, tem problema aí. Por isso a gente faz a mobilidade. Eu brinco que nós, povo Guarani, somos conhecidos cientificamente como povo nômade, e somos tradicionalmente o povo da mobilidade. Esse movimento é o que dá vida pra toda essa diversidade das plantas, dos animais e dos seres humanos.

Sofia: - Nossa, maravilhoso Kerexu! Tem várias pessoas fazendo comentários, mandando carinhas com corações. É muito bonito, mesmo, escutar e conhecer um pouco mais da cultura de vocês. Fiquei pensando que a prática de fazer o artesanato permite a manutenção de todo este saber associado ao gênero e o reconhecimento da importância do feminino. Tudo isso ficou muito evidente quando você mostrou aquela cesta, de reconhecer a importância da complementaridade e valorizar tanto o aspecto feminino, como o masculino. Os dois são importantes para que exista a cesta, para que exista tudo o que vai ser criado daí. Mas vamos para mais uma pergunta. A gente tem acompanhado esse crescimento do movimento das mulheres indígenas, e da luta da mulher indígena. Eu queria que você compartilhasse um pouco sobre as discussões atuais que estão acontecendo no âmbito do Brasil. Quais são as demandas? 
Kerexu: - Esse ano, a gente tá fazendo um debate muito forte. É um debate interno mesmo, pra gente desconstruir tudo que foi construído e que foi dado um certo "valor" dentro da sociedade, que é esta questão de separar o homem e a mulher. Então, assim, pra mim isso também foi muito forte durante a campanha que eu fui candidata em 2018, porque dentro da proposta da campanha tinha a questão do feminismo e se discutiam várias coisas voltadas pra questão da mulher. No período que eu era Cacica, eu já entendia o valor da mulher, mas também o valor do homem. Então isso fez com que eu me silenciasse por um tempo. Não sei se vocês perceberam, mas eu nunca quis falar muito "eu sou feminista" ou "tenho esta bandeira de defesa", embora eu entenda que tudo isso é muito importante ser discutido. Então, é com muito cuidado também e muita delicadeza que a gente trouxe este debate para o meio das mulheres indígenas. Entender todo este papel do universo, da Mãe Terra, e de tudo que a gente vem passando hoje, por toda essa doença que a Terra está passando hoje. A gente começou a fazer mais estes debates internos e foi muito assustador. De tudo o que a gente trouxe para debater, o mais forte é a questão da violência, da violência contra as mulheres. É algo assustador! É muita coisa, que, às vezes, a gente não consegue imaginar que isso realmente esteja acontecendo. Dentro das aldeias, fora das aldeias, o quanto a mulher é repelida nessa sociedade, e ela não consegue encontrar nenhum amparo, nem fora, nem dentro da aldeia, às vezes, nem até por outras mulheres. Acabam não encontrando esse apoio. Quando eu fui escolhida para ser coordenadora da Comissão Guarani Yvyrupa (CGY), deu um frio na barriga. Desde 2016, eu tinha decidido me afastar um pouco dessa linha de política, de liderança indígena, até porque nesse período eu fui muito perseguida, muito ameaçada. A minha família foi muito ameaçada. Eu acabei parando, me retirando um pouco e falando que eu não ia mais atuar como liderança. Mesmo assim, dentro da aldeia, acabava fazendo esse papel de liderança. Na assembleia Guarani, que teve em maio do ano passado, no Morro dos Cavalos, eu fui apontada pra ser coordenadora da Comissão, e de novo, foi no meio de um monte de homens. Eu era a única mulher que havia sido apontada para ser coordenadora nacional do povo Guarani. Nossa, naquela hora me deu um frio na barriga, por que eu já tinha passado por isso na minha aldeia, aqui dentro do estado e agora teria que ser nacional. Eu olhava para algumas mulheres que estavam na assembleia e elas estavam com os olhos brilhando - "Vai lá, vai lá". Nossa! Naquele momento eu falei: "Eu vou aceitar, sim, ser coordenadora da Comissão Guarani Yvyrupa e é por elas", e mostrei as mulheres que estavam lá, por elas! E é pelas mulheres que eu vou falar, pelas mulheres que eu vou lutar e é pelas mulheres que eu estou aqui hoje, exercendo essa função de coordenadora da comissão do povo Guarani, do território Guarani. Aquele momento foi 
muito legal, porque eu tive muito apoio e quando eu entrei na comissão, comecei a envolver as mulheres nas funções. $\mathrm{Eu}$ estou passando por um processo muito bonito, de transformação mesmo do nosso território, e bem forte também, pois está associado às sementes. Um dos meus propósitos dentro da comissão, que eu trago como bandeira e que quero colocar também pra vocês que estão acompanhando, é o propósito de reflorestar a Mata Atlântica. Nós, povo Guarani, somos o povo da floresta Mata Atlântica. A nossa floresta é a floresta mais devastada de todos os biomas, então este é o meu propósito dentro da comissão Guarani. Começar a curar todos os males, já que a gente está fazendo isso dentro dos encontros com as mulheres. Pra gente poder consagrar essas sementes, consagrar estas mudas, e fazer este plantio das sementes a gente precisa curar. E como é que a gente vai curar? É com essas mulheres que foram violentadas, que foram violadas de diferentes formas. Hoje elas conseguem falar e por pra fora tudo o que elas passam, tudo que elas passaram, dentro de suas aldeias e fora delas, então esse é o meu objetivo. Graças a Deus a gente está conseguindo e hoje temos um grupo maior de mulheres. Quando a gente fez o primeiro encontro nacional, a gente tinha mais de 300 mulheres Guaranis. Foi a primeira vez na vida que a gente parou para falar sobre nós mesmas. Então essa é a nossa missão a partir de hoje. Eu sei que é difícil onde a gente está vivendo, inclusive aqui em Santa Catarina. Mas em toda a região da floresta Mata Atlântica é uma briga grande, pois onde tem um pouquinho de floresta é uma disputa muito grande. Onde não tem essas brigas é onde estão os esgotos, os asfaltos. Eu falo assim: "Gente, nós vamos ter que ter muita coragem e enfiar a mão na merda mesmo, pra limpar esses esgotos, e também bater nossa mão nesses asfaltos pra gente poder fazer essa floresta voltar". Então, a gente está com este propósito.

Sofia: - Que bom saber disso, dessa força e de toda essa mobilização. Bom saber desse processo de vocês estarem olhando para as mulheres, buscando essa cura, que é a cura também da Terra. Outra questão, Kerexu, no laboratório de Ecologia Humana e Etnobotânica nós temos este propósito de estar construindo pontes, de estar fortalecendo essas parcerias com os Povos Tradicionais. Então, também queria escutar de ti, de que forma que nós, enquanto academia, podemos estar atuando e colaborando realmente com vocês.

Kerexu: - Então, dentro de todo este sistema que foi criado, deste sistema capitalista, a gente está em um momento que nos remete a olhar pra Terra. Todo mundo sabe que a gente está passando por um período muito difícil. Pro sistema, é um momento de crise, pra nós é um momento de doença. Mas a gente está em um momento de cura, em um processo de 
cura. Eu venho de uma caminhada de professora, liderança e agora também de coordenadora da comissão. De novo, estou dentro dessa luta, dessa defesa, tanto pelo território, mas também agora com esse compromisso com a questão do reflorestamento da Mata Atlântica. Esse, pra mim, é o papel fundamental. Hoje chega essa pandemia e nos remete, de novo, todo mundo pra Terra. Quem não entendeu esse chamado, quem não entendeu este recado, infelizmente, não tem muito o que se fazer. Tudo que está acontecendo hoje é uma reação daquilo que a gente fez lá trás, daquilo que a sociedade fez lá atrás. A gente tem a exploração do nosso território, que é a terra mesmo, mas tem essa produção de alimentos saudáveis, essa produção de medicina, tudo dentro desse sagrado. Nossas nascentes, que são as nossas águas, umas poluídas e outras de água potável, estão sendo exploradas financeiramente, vendidas e entregues para outros países. Isso faz com que muitos de nós sejam obrigados a pagar pela água e ainda a gente não tem certeza se estamos tomando uma água boa. Estamos nessa função, que é uma função mundial, que precisamos fazer para reparar e para curar mesmo a terra. A gente sempre fala que nós não temos nenhum outro planeta, caso este daqui não funcione mais. Nós não temos. Todos precisamos ter essa consciência e essa ciência também, de que não existe ninguém melhor do que ninguém. Não existe um mais rico do que o outro, porque nós sobrevivemos da terra, nos alimentamos da terra, é ela que nos dá o alimento. Nós precisamos de água para sobreviver, nós precisamos de luz para sobreviver, nós precisamos de ar para respirar e sobreviver. Essa é a nossa maior riqueza. Infelizmente, foi nesse sentido que a Terra foi ferida, que ela foi violentada. Então, hoje a gente precisa ter, como eu falei, essa consciência e essa ciência, de que é isso mesmo que a gente precisa fazer pela Terra. Eu acho muito bacana quando a gente se especializa dentro de uma área, como eu, que fui para a universidade fazer uma licenciatura e fui para a linha da gestão ambiental. Pra mim hoje está servindo muito, pelos conhecimentos, pelas trocas de conhecimento, porque eu já sou ambientalista nata. Eu sempre falo que tenho três formações ambientais: uma que eu já nasci ambientalista; outra porque meu povo me escolheu para defender este ambiente; e também pela graduação, que trago este conhecimento que é muito válido. É muito válido, pois eu consigo colocar em prática dentro da Terra Indígena Morro dos Cavalos esta questão da gestão territorial, de fazer essa gestão do meio ambiente onde eu estou vivendo, e também de todo o território. Essa gestão traz muito forte a potência de conhecer a parte científica, e que eu falo que graças a Deus que na floresta Mata Atlântica a maioria das plantas estão registradas cientificamente com o nome Guarani. O que está faltando agora são as ações. Essa é a parte que não está funcionando, tem alguma coisa errada nesse meio 
que não está tendo vida, que está com uma deficiência, é quando não tem movimento. Eu posso ter a ideia, falar, mas se eu não me movimentar e fazer, o negócio não vai funcionar. Então a gente precisa ser completo, a gente precisa estar completo pra gente ser saudável e pra gente conseguir curar esta Terra. Mas aí as pessoas perguntam assim: "Mas eu moro na cidade grande, eu moro num apartamento, não tem terra dentro da minha casa, às vezes, levo uns vasinhos, planto umas sementinhas lá, pra dar isso, dar aquilo, não tem como fazer isso". Bom, mas tendo vontade, já vai ajudar bastante. Por exemplo, talvez nas aldeias, ou em alguns lugares onde têm esses terrenos, tenha toda essa boa vontade de fazer, mas falte também essa questão de insumos, de sementes, de fazer uma pesquisa. Nosso solo, como eu falei hoje, de tanto a Terra ser violentada, ela está fraca e a gente precisa trabalhar isso também dentro dessa questão do solo. Hoje a gente tem a ciência, a universidade tem essa questão científica, que entende de como fazer essa recuperação. A gente tem muitos apoiadores aqui no Morro dos Cavalos, graças a Deus! Eu fico muito feliz porque eu tenho muitos amigos e pessoas de espírito bom. Hoje, a gente está fazendo o reflorestamento de cinco hectares de uma área que era tomada por pinus. Quando passar a pandemia, vocês vão ver o Morro dos Cavalos transformado. Eu estou emocionada de conseguir fazer isso. Nós conseguimos retirar esses pinus e estamos plantando uma área enorme de comida, são árvores frutíferas, são plantas medicinais, uma diversidade de plantas nativas que a gente está colocando aqui, buscando onde tem e buscando esses apoios. A gente tem um grupo que está nos acompanhando e uma campanha de arrecadar recursos para comprar ferramentas, para buscar as coisas que não têm aqui e a gente acha em outro lugar. Faz três anos que estamos planejando isso, e essa semana a gente já alcançou $50 \%$ do nosso projeto em execução. Não temos apoio de órgão estadual, nem ganhamos edital, o que temos é o apoio de todo mundo que está ajudando, que está contribuindo. Tem gente que faz doação de plantas, outros de alimentos, outros fazem doação de ferramentas e assim a gente está conseguindo fazer esta construção, reconstruindo o Morro dos Cavalos. Eu deixo aqui este convite, mais uma vez esse convite aberto, pra todos que queiram, pra todos que sentirem este chamado, essa coisa de arrepiar o peito, uma batida forte no coração, de convidar vocês para reflorestar a nossa floresta. Convido pra conhecer um pouco de nós, um pouco desse universo, do nosso território, de onde a gente pisa, de saber que nós, o povo Guarani, a gente busca as origens, a gente procura saber: "Qual a origem da mulher? Qual a origem do homem?” Pra tudo tem uma história. Quando a gente entende essa história, a gente sabe que é parte disso e a coisa fica muito mais fácil. Este é o convite que eu faço pra todos que estão acompanhando, e que queiram de alguma forma ajudar, não só aqui no Morros dos Cavalos, 
mas em outras aldeias, em outros lugares que estão fazendo este tipo de trabalho. Quanto mais a gente começar este trabalho de formiguinha, mas a gente consegue transformar e amenizar um pouco desta dor que a gente está passando nesse momento.

Sofia: - Vamos indo pros momentos finais, imagino que as pessoas adorariam continuar escutando a Kerexu por muito tempo, várias pessoas compartilharam isso nos comentários. Mas vamos precisar encerrar, pois acabamos excedendo o tempo de uma hora de conversa. Nesse momento final, quero deixar livre para mais algum recado, falar mais alguma coisa. Te agradeço muito, mesmo, pela tua disponibilidade de estar aqui com a gente. Nós sabemos das demandas que vocês têm, do movimento político e das questões da comunidade e da família. Mesmo assim, abriu espaço para estar com a gente. Pra nós é muito importante te escutar, escutar as vozes indígenas, e pelos comentários podemos perceber que realmente tocou muito o pessoal que está assistindo.

Kerexu: Que bom! Pra mim também é muito importante participar e conversar com as pessoas que querem ouvir. De alguma forma, acho que estou fazendo essa função de Kerexu, de fazer brotar as sementes, sejam elas humanas, plantas, animais e onde existirem seres vivos. É fazer esta quebra de dormência. "Kerexu” dentro da minha função, eu sou uma mãe, uma matriz. "Yxapyry" sou a gota de orvalho, então eu sempre estou aí. Te agradecer também pelo convite, mais uma vez a gente estar conversando. Estou à disposição, no que eu puder contribuir, dentro dessa luta que a gente vem travando de salvar esse nosso planeta, e é urgente. Eu acho que quanto mais nós estarmos juntos, mais pessoas ouvirem, mais pessoas falarem e contribuírem, teremos mais ações. A gente precisa urgentemente fazer essas ações! Agradeço a todos que participaram aqui junto com a gente nesta live, que entra, cai, sai, essas coisas assim...

Sofia: (risos) Sim, que persistiram com a gente!

Kerexu: - Sim, que continuaram junto com a gente aqui. É muita gratidão, eu fico muito feliz mesmo e aquece a minha esperança, aquece o coração e nos fortalece, para que a gente dê seguimento a essa missão que a gente trouxe pra fazer nesse mundo. Então só agradeço. Sofia: - É bem isso mesmo que você falou, Kerexu, de dar esperança. Esta live, esta conversa, nesse momento difícil que todos nós estamos vivendo. É de aquecer realmente nosso coração e nos dar essa energia e essa esperança que a gente precisa pra caminhar daqui pra frente. Muita gratidão, vamos manter o contato, estamos juntas.

Kегехи: - Beijo!

Sofia:- Beijo! 


\section{AGRADECIMENTOS}

Agradecemos a Graziela Dias Blanco e a Lorayne Reinehr Nobre pela leitura crítica e considerações realizadas para a melhoria da versão final do texto. Agradecemos a Natalia Hanazaki pelas contribuições no planejamento e organização desse artigo e ao ECOHE pelo apoio na realização e divulgação da live.

\section{REFERÊNCIAS BIBLIOGRÁFICAS}

ANDRADE, J. H.C. Intercâmbio de plantas na medicina Mbyá-Guarani no sul do Brasil. Dissertação (mestrado em Biologia de Fungos, Algas e Plantas) - Centro de Ciências Biológicas, Universidade Federal de Santa Catarina, Florianópolis. 2019. 109 f.

BLANCO, D. G. Estudo Etnobotânico e Morfoanatômico de espécies de Orchidaceae utilizadas por grupos Guarani. Dissertação (mestrado em Biologia de Fungos, Algas e Plantas) - Centro de Ciências Biológicas, Universidade Federal de Santa Catarina, Florianópolis. 2017. $155 \mathrm{f}$

FEDERICI, S. Calibã e a bruxa. Mulheres, corpo e acumulação primitiva. São Paulo: Elefante, 2017, 460 p.

GAARD, G. Ecofeminism revisited: rejecting essentialism and re-placing species in a material feminist environmentalism. Feminist Formations, v.23, n. 2, p. 26-53, 2011.

RIBEIRO, D. Lugar de fala- Feminismos Plurais. São Paulo: Pólen, 2019. 111 p. 